\title{
Gamma Rays Interactions with Strontium Borate Glasses Doped with First-Row Transition Metal Oxides
}

\author{
H. A. El Batal ${ }^{1}$, F. H. ElBatal ${ }^{1}$, and A. M. Abdelghany ${ }^{2}$ * \\ ${ }^{I}$ Glass Research Department, National Research Center, Dokki, Cairo, Egypt \\ ${ }^{2}$ Spectroscopy Department, Physics Division, National Research Center, Dokki, 12311, Cairo, Egypt
}

\begin{abstract}
Optical and FT infrared absorption spectroscopic studies were carried out to investigate the spectral properties of prepared undoped and $3 \mathrm{~d}$ transition metal oxides-doped-strontium borate glasses. The same measurements were repeated after gamma-irradiation of the samples with a dose of $8 \mathrm{Mrad}\left(8 \times 10^{4} \mathrm{~Gy}\right)$. The undoped strontium borate glass before irradiation exhibits a broad strong UV absorption which is related to unavoidable trace iron ( $\mathrm{Fe}^{3+}$ ions) impurities contaminated within the raw materials used for the preparation of this glass. Examination of the optical spectra of TMs-doped glasses reveals extra characteristic UV-visible bands due to the respective doping $3 \mathrm{~d}$ transition metal ions. Gamma irradiation of the undoped strontium borate glass produces induced defects within the UV and visible regions while the TMsdoped glasses reveal limited variations due to shielding effects of some TM ions in this specific host strontium borate doped glasses towards gamma irradiation.

Infrared absorption spectra of the prepared glasses reveal characteristic vibrational bands due to both triangular and tetrahedral borate groups within the wavenumber range $1200-1600 \mathrm{~cm}^{-1}$ and $800-1200 \mathrm{~cm}^{-1}$, respectively. The addition of $3 \mathrm{~d}$ TM dopants $(0.2 \%)$ causes no distinct variations in the main IR vibrational bands because of the low level of TM ions and their housing in the glass network structure as modifiers. Also, gamma irradiation causes no changes in the number or position of the main characteristic IR vibration bands due to the quite stability of the base glass containing high content of heavy metal $\left(\mathrm{Sr}^{2+}\right)$ cations.
\end{abstract}

Keywords: FTIR spectroscopy; gamma irradiation; strontium borate glass; transition metals; UV-visible.

\section{INTRODUCTION}

Glasses containing $\mathrm{B}_{2} \mathrm{O}_{3}$ belong to a specific system of glass that exhibit considerable interest from both fundamental scientific and technological point of view. Borate based glass compositions are of numerous commercial applications such as chemically durable and heat-resistant neutral glass, fiber glass, encapsulation of radioactive nuclear wastes and recently as biomaterial [1-5]. Also, some borate glasses exhibit piezoelectric, electro-optic and fast ionic properties beside the ability when crystallized to perform second harmonic generation and nonlinear optical activity $[1,6]$.

Alkaline earth oxides $(\mathrm{CaO}, \mathrm{SrO}, \mathrm{BaO})$ behave like alkali oxides when reacted with $\mathrm{B}_{2} \mathrm{O}_{3}$ to form binary borate glasses containing both triangular and tetrahedral boron groups as evidenced by infrared and Raman spectra [7, 8].

Glasses containing transition metal oxides (TMOs) possess valuable and interesting optical and electrical properties and have been applied as acid-base indicators, radiation dosimeters and also as radiation-shielding candidates [9-13].

*Address correspondence to the author at the Spectroscopy Department, Physics Division, National Research Center, Dokki, 12311, Cairo, Egypt; Tel: +2 01221133152 ; Fax: +2 0233370931 ;

E-mail: a.m_abdelghany@yahoo.com
Both optical and electrical properties of such TMscontaining glasses depend on the presence of transition metal ions in varying valencies or coordination states.

Previous optical investigations of $3 \mathrm{~d}$ transition metal ions in lithium borate glass [11] and sodium borate glass [12] have indicated that such alkali borate glasses promote the existence of TM ions in their higher valence or tetrahedral coordination states. Also, some of these $3 \mathrm{~d}$ transition metal ions reveal shielding behavior towards successive gamma irradiation.

The action of gamma-ray irradiation on glass, initiates the excitation of electrons from the valence band if the incident energy is greater than the band gap. If $\mathrm{E}>1 \mathrm{KeV}$, the electrons are excited by the Compton Effect [14]. The electron that travels through glass will either recombine with positively charged holes and become trapped to form color centers, or if the energy is sufficiently high, it produces a secondary electron cascade by knock-on collisions with other bound electrons.

Finally, when electron's energy becomes too low to ionize other electrons, they will either be trapped or recombine with holes. In other words the primary effect of glass exposure to ionizing sources is ionization rather than displacement. The trapping sites for electrons or holes can be either 
pre-existing flaws in the glass matrix, such as oxygen vacancies or non-bridging oxygens, or flaws created by the high energy electrons themselves. A further trapping sites include cations which substitute for the network formers in the glass, network-modifying cations such as alkalis, multivalent cations such as (TM ions or rare earth ions).

This work involves investigations of both optical and FT infrared absorption spectra of base binary strontium borate glass (of the composition mol\% $60 \mathrm{~B}_{2} \mathrm{O}_{3}, 40 \mathrm{SrO}$ ) together with other glassy samples with the same base composition and containing additional $0.2 \%$ of any of the $3 \mathrm{~d}$ transition metal oxides $\left(\mathrm{TiO}_{2}, \mathrm{~V}_{2} \mathrm{O}_{5}, \mathrm{Cr}_{2} \mathrm{O}_{3}, \mathrm{MnO}_{2}, \mathrm{Fe}_{2} \mathrm{O}_{3}, \mathrm{CoO}, \mathrm{NiO}\right.$, $\mathrm{CuO}$ ) before and after gamma irradiation with a gamma dose of $8 \mathrm{Mrad}\left(8 \times 10^{4} \mathrm{~Gy}\right)$. Gamma rays are the most efficient and high penetrating source and measurements of the glasses can be done safely after irradiation.

This combined spectral measurements study is expected to identify the states of TMs in this host glass and the radiation induced defects generated from the studied glasses by gamma irradiation. Also, the response of the effect of gamma irradiation on the studied glasses will facilitate the statement of the suitability of such glasses as radiation color indicator or radiation shielding candidates.

\section{EXPERIMENTAL DETAILS}

\subsection{Preparation of Glasses}

The glasses were prepared from chemically pure finegrained grade materials including orthoboric acid for $\mathrm{B}_{2} \mathrm{O}_{3}$, anhydrous heavy strontium carbonate for $\mathrm{SrO}$, and the $3 \mathrm{~d}$ transition metal oxides $\mathrm{TiO}_{2}, \mathrm{~V}_{2} \mathrm{O}_{5}, \mathrm{Cr}_{2} \mathrm{O}_{3}, \mathrm{MnO}_{2}, \mathrm{Fe}_{2} \mathrm{O}_{3}$, $\mathrm{CoO}, \mathrm{NiO}$ and $\mathrm{CuO}$ were introduced separately within the batches as additional $0.2 \mathrm{wt} \%$.

Melting was carried out at $1200{ }^{\circ} \mathrm{C}$ for 90 minutes under normal atmospheric condition in platinum crucibles. The crucibles were rotated at intervals to promote homogeneity to the melts. After complete melting and homogenizing, the melts were cast into warmed stainless steel molds of the required dimensions. The prepared glassy samples were carefully and immediately transferred to a muffle furnace regulated at $420{ }^{\circ} \mathrm{C}$ for annealing. The muffle with the samples inside was left to cool down after 1 hour to room temperature at a rate of $30^{\circ} \mathrm{C} /$ hour. The chemical composition of the studied glasses was found to be the same as the batches composition due to the presence of high percent ( $45 \mathrm{~mol} \%$ ) of heavy metal oxide ( $\mathrm{SrO}$ ) which shows no sublimation or volatility like alkali borate glasses.

\subsection{UV-visible Absorption Measurements}

Ultraviolet and visible absorption spectra were immediately measured for highly polished glass samples of equal thickness $(2 \mathrm{~mm} \pm 0.1 \mathrm{~mm})$ before and after gamma irradiation using a recording double beam spectrophotometer (type JASCO corp.v-570, Rel-OO, Japan) covering the range from 190 to $1100 \mathrm{~nm}$.

\subsection{Infrared Absorption Measurements}

The FTIR absorption spectra of both the prepared undoped strontium borate glass and the TM-doped samples were measured at room temperature in the wave number range $400-2500 \mathrm{~cm}^{-1}$ by a Fourier transform computerized infrared spectrometer type, Nicolet $i S 10$, USA. The prepared samples as pulverized powder were mixed with $\mathrm{KBr}$ in the ratio $1: 100 \mathrm{mg}$ (powder: $\mathrm{KBr}$, respectively). The weighed mixtures were then subjected to a pressure of 5 tons $/ \mathrm{cm}^{2}$ to produce clear homogeneous discs. The infrared absorption spectra were measured immediately after preparing the desired discs and the same measurements were repeated for the prepared samples after gamma irradiation with a dose of 8 Mrad.

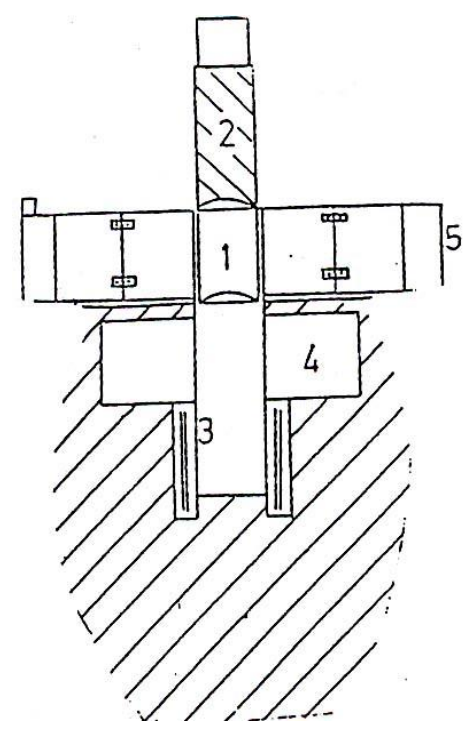

Scheme (1-a). A schematic diagram of gamma cell used for irradiation process.

1- Irradiation chamber 2- Irradiation drawer

3- $\mathrm{Co}^{60}$ irradiation source 4- Inner head plug

5- Hinged lead collar swing clear of irradiation chamber.

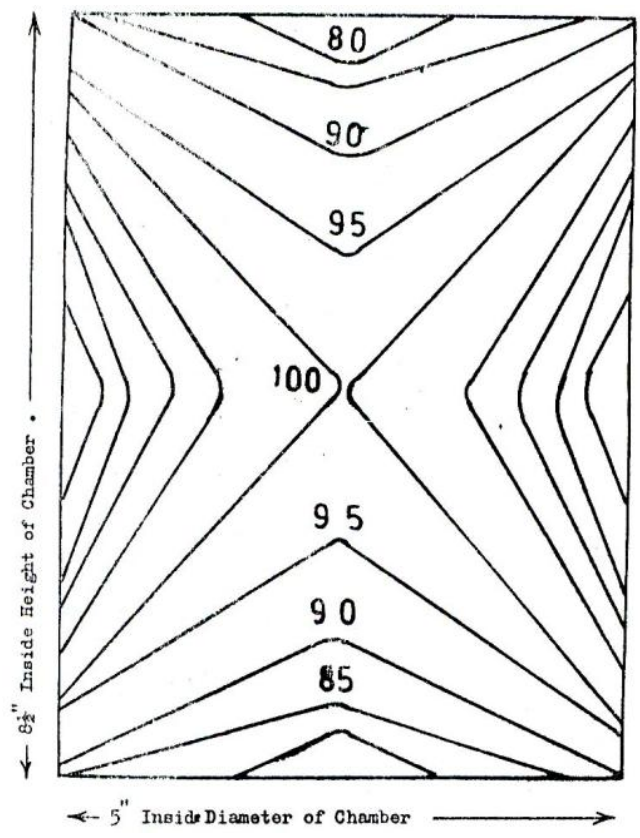

Scheme (1-b). Isodose counter curve. 


\subsection{Gamma Irradiation Facility}

$\mathrm{A}^{60} \mathrm{Co}$ gamma cell $(2000 \mathrm{Ci})$ was used as a $\gamma$-ray source with a dose rate of $1.5 \mathrm{~Gy} / \mathrm{sec}(150 \mathrm{rad} / \mathrm{s})$ at a temperature of $30^{\circ} \mathrm{C}$. The investigated glass samples were subjected to the same gamma dose every time. Using a Fricke dosimeter, the absorbed dose in water was utilized in terms of dose in glass. No cavity theory correction was made. Each glass sample was subjected to a final gamma dose of $8 \times 10^{4} \mathrm{~Gy}(8 \mathrm{M} \mathrm{rad})$. Scheme 1-a represents a schematic diagram of gamma cell cross section used for sample irradiation) while Scheme 1-b represent isodose counter curves.

\section{RESULTS AND DISCUSSION}

\subsection{Optical Absorption of Base Undoped and TMs Doped Strontium Borate Glasses}

\subsubsection{Optical Absorption of Undoped Strontium Borate Glass}

Fig. (1) illustrates the UV-visible absorption spectra of the undoped strontium borate glass before and after gamma irradiation. The optical spectrum reveals before irradiation strong and wide absorption extending from 200 to about 400 $\mathrm{nm}$ and showing three small peaks at about 220, 320 and 360 $\mathrm{nm}$ and no visible bands could be identified. On subjecting this glass to gamma irradiation (8Mrad), the UV absorption increases intensely with parallel behavior with the same peaks and the visible absorption shows a new induced broad visible band centered at about $580 \mathrm{~nm}$.

Sigel and Ginther [15] and Cook and Mader [16] have separately recognized strong ultraviolet absorption bands in various undoped commercial glasses. They have attributed that such UV absorption bands are originated from unavoidable trace iron $\left(\mathrm{Fe}^{3+}\right.$ ions) impurities contaminated within the raw materials used for the preparation of these commercial glasses.

Duffy [17] has classified different charge transfer UV absorptions identified in various glasses and has assumed that the strong charge transfer UV bands observed from

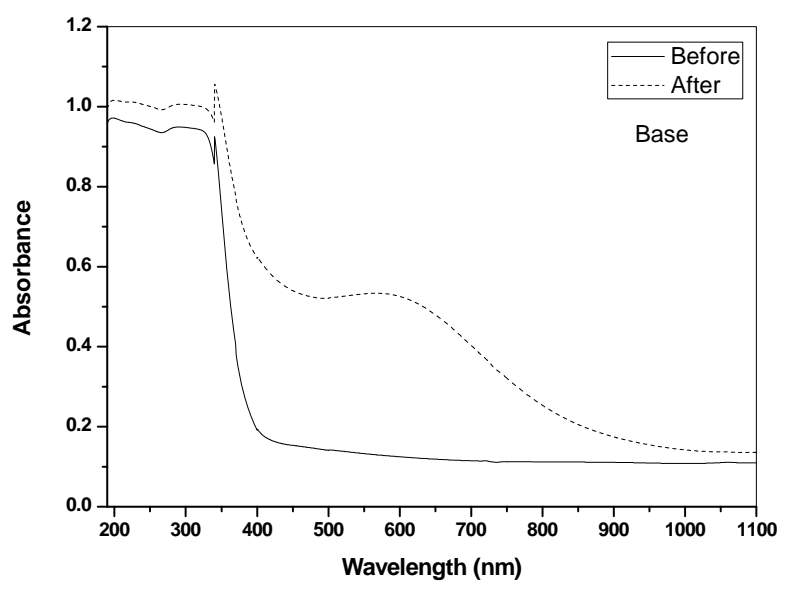

Fig. (1). UV-visible absorption spectra of the binary strontium borate glass before and after gamma irradiation. some trace impurities (e.g. $\mathrm{Fe}^{3+}, \mathrm{Cr}^{6+}$ ) are due to electron transfer mechanisms and are clearly identified even if the impurities are within the ppm level.

Strong UV bands in undoped lead borate glass [18] and undoped sodium borate glass [19] have been identified and attributed to trace ferric ions $\left(\mathrm{Fe}^{3+}\right)$ present as impurities even in the ppm level within the chemicals used for the preparation of glasses.

Based on previous assumptions, the observed strong UV bands at about 235, 310 and $350 \mathrm{~nm}$ are related to trace ferric ions $\left(\mathrm{Fe}^{3+}\right)$ present as impurities $\left(\mathrm{Fe}^{3+}\right.$ ions) contaminated within the raw materials used for preparation of the undoped strontium borate glass.

To interpret the effect of gamma irradiation on the undoped binary strontium borate glass, the following assumptions are introduced.

1. Gamma irradiation is accepted to produce pairs of electrons and positive holes generated during the irradiation process [14].

2. The observed increase of the intensity of the UV absorption can be related to proposed photo-chemical reactions of some iron impurities present as $\mathrm{Fe}^{2+}$ which is oxidized to $\mathrm{Fe}^{3+}$ by absorbing positive holes $[14,18$, 19]. The species of $\mathrm{Fe}^{3+}$ ions are known to absorb strongly within the UV region when present as traces while $\mathrm{Fe}^{2+}$ ions absorb at the wavelength $1100 \mathrm{~nm}$.

The generation of the induced visible band at about 580 $\mathrm{nm}$ upon irradiation of the undoped glass is assumed to be produced from holes trapped on borate network as boron oxygen hole centers $[\mathrm{BOHC}]$ or nonbridging oxygen hole center $[\mathrm{OHC}]$ as suggested by several authors $[18,19]$.

\subsubsection{Optical Absorption of TMs-doped Glasses}

Fig. (2) reveals the optical absorption of 3d TMs-doped samples with different TM ions before and after gamma irradiation and the spectral results can be summarized as follows:

\subsubsection{Titanium-doped Glass}

This Ti-doped glass reveals before irradiation strong UV absorption extending to about $370 \mathrm{~nm}$ and exhibiting two distinct peaks at about 235 and $310 \mathrm{~nm}$ and with no observed visible bands. The gamma irradiated Ti-doped sample shows the same spectral characteristics as before irradiation with slight decrease in the intensity of the UV absorption and slight increase in the visible spectral curve but with slight curvature at about $580 \mathrm{~nm}$.

Titanium ions are accepted to be able to exist as trivalent and tetravalent oxidation states in glasses [20]. The observed absorption spectrum in this $\mathrm{TiO}_{2}$-glass is restricted to strong UV absorption with only two distinct peaks at 235 and 310 $\mathrm{nm}$. Such UV bands are previously assumed to be due to trace iron impurities (specifically $\mathrm{Fe}^{3+}$ ions) and no further bands are observed in the visible region. Tetravalent $\mathrm{Ti}^{4+}$ ion belongs to $\mathrm{d}^{0}$ configuration and did not exhibit visible bands 
but trivalent $\mathrm{Ti}^{3+}$ ions belong to $\mathrm{d}^{1}$ configuration and exhibit a visible band at $460-480 \mathrm{~nm}$. The absence of any visible band in the spectrum of this glass before irradiation indicates that $\mathrm{Ti}^{3+}$ ions are almost absent or within low percent to be detected. Gamma irradiation causes a slight decrease of the intensity of the UV bands, and no visible band could be identified. This can be explained by assuming that some of $\mathrm{Fe}^{3+}$ ions absorb librated electrons during the irradiation process

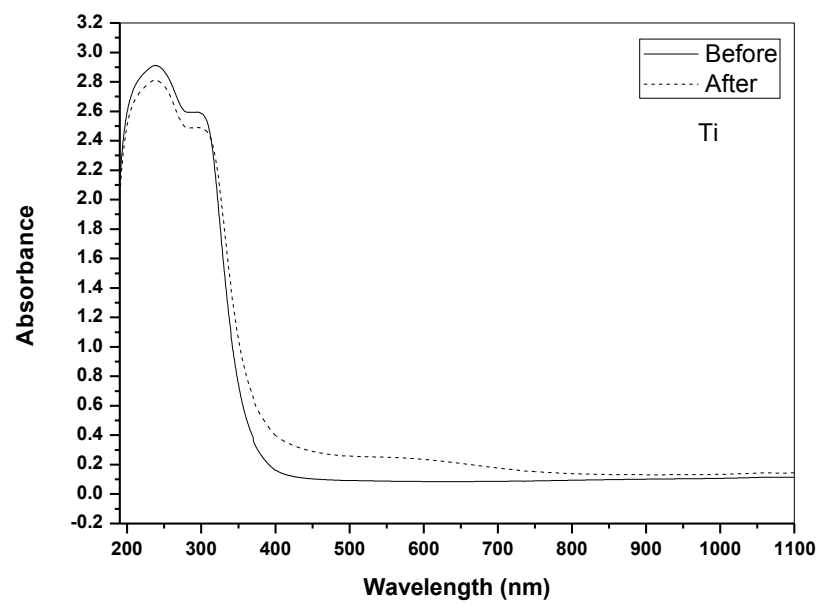

(a)

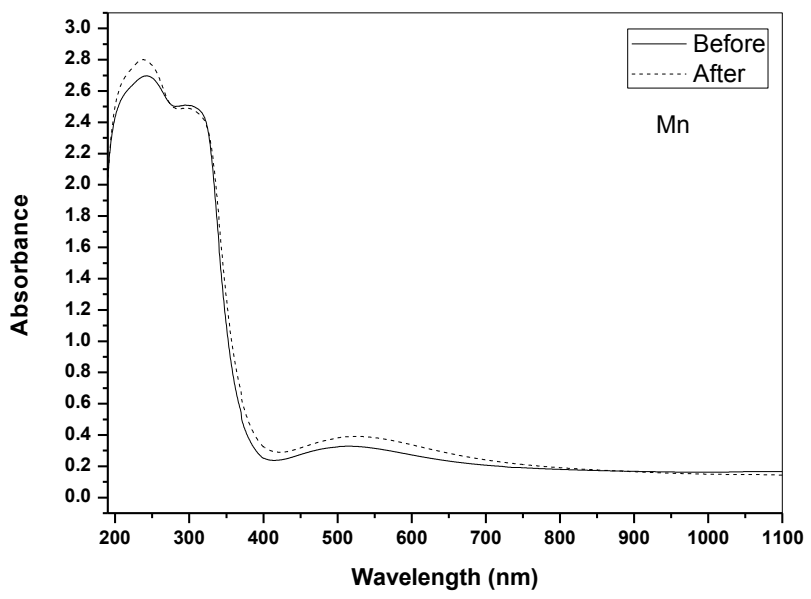

(c)

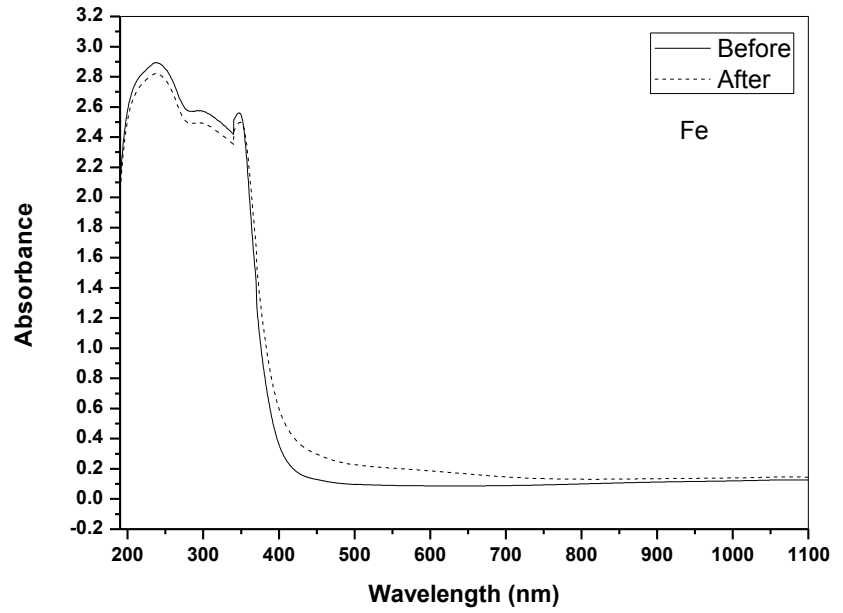

(e) and are transformed to $\mathrm{Fe}^{2+}$ ions. These formed $\left(\mathrm{Fe}^{2+}\right)$ ions are known to absorb strongly only in the near IR region at about $1100 \mathrm{~nm}$, The experimental optical results indicate that the presence of titanium ions partly suppress the action of gamma irradiation and no distinct induced bands are formed in the visible region as observed in the undoped sample at about $580 \mathrm{~nm}$ but only a slight curvature due to the shielding effect of titanium ions.

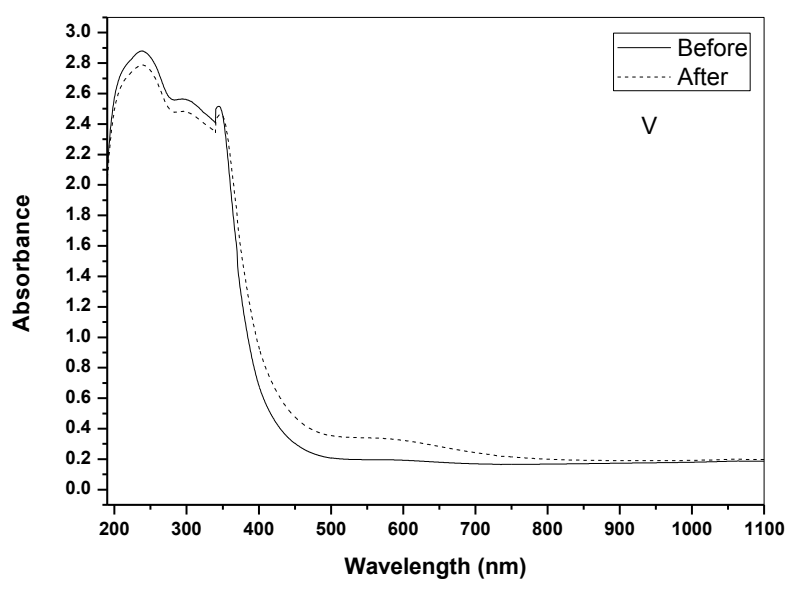

(b)

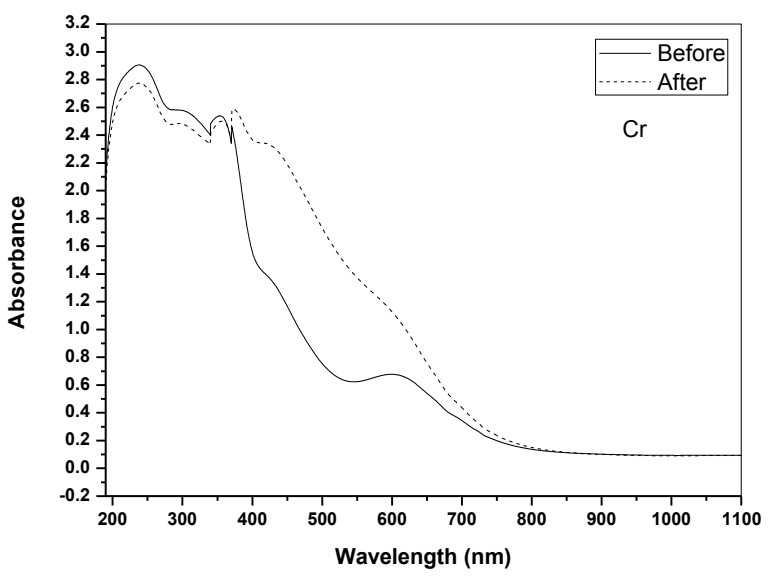

(d)

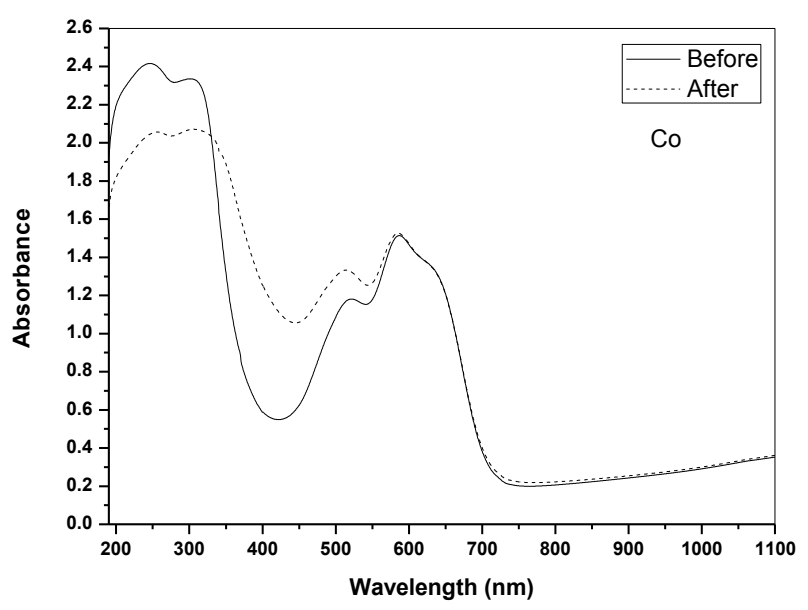

(f) 


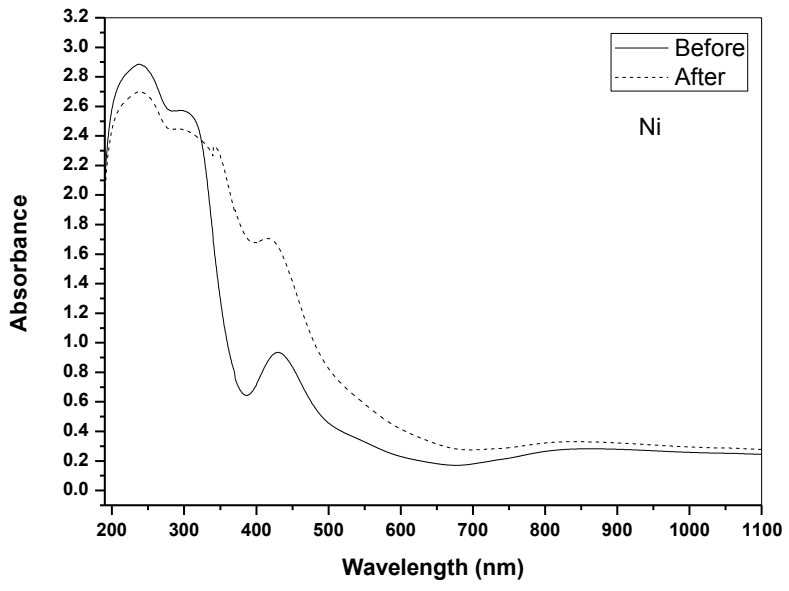

(g)

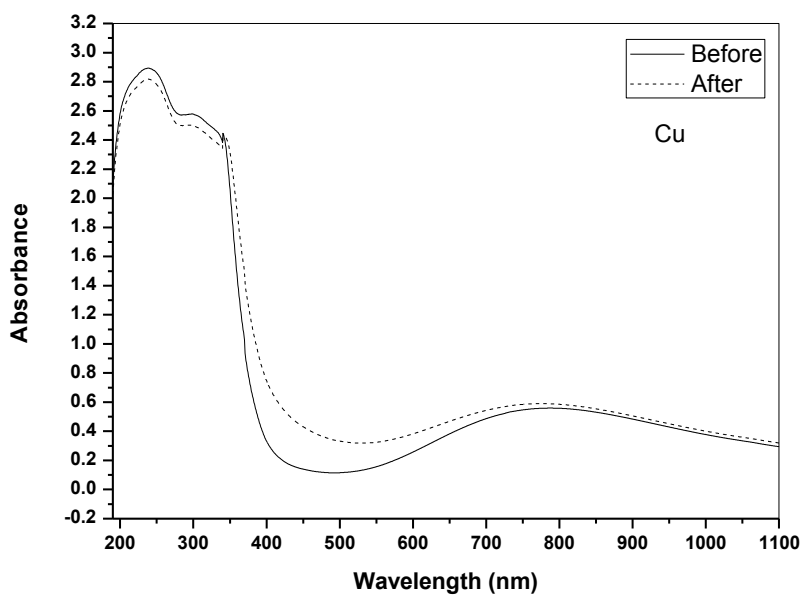

(h)

Fig. (2). optical absorption of 3d TMs-doped samples before and after gamma irradiation.

\subsubsection{Vanadium-doped Glass}

The V-doped sample exhibits strong and wide ultraviolet absorption extending from 200 to $400 \mathrm{~nm}$ and showing three distinct peaks at about 235, 310 and $350 \mathrm{~nm}$ and a slight curvature in the visible region centered at $580 \mathrm{~nm}$. Upon gamma irradiation, the spectral characteristics remain almost constant with very slight variation in the intensities with curvature around $580 \mathrm{~nm}$.

Vanadium ions are accepted to be able to exist in three valence forms in glasses, namely the trivalent, tetravalent and pentavalent states $[10,21,22]$. The trivalent vanadium $\left(\mathrm{V}^{3+}\right)$ ions exist in distorted octahedral coordination with oxygens and exhibit two characteristic absorption bands at $350-400 \mathrm{~nm}$ and $580-600 \mathrm{~nm}$. The tetravalent vanadium $\left(\mathrm{V}^{4+}\right)$ ions are assumed to exist as vandyle $\left(\mathrm{VO}^{2+}\right)$ ions and exhibit three weak peaks at 420, 760-860 and $1000 \mathrm{~nm}$ because of the spin forbidden nature. The pentavalent vanadium $\left(\mathrm{V}^{5+}\right)$ ions correspond to the $\mathrm{d}^{0}$ configuration and will not give rise to any d-d transition but give an UV band at 350$380 \mathrm{~nm}$. The optical absorption reveals three UV peaks at 235,310 and $360 \mathrm{~nm}$ and a small visible peak at $580 \mathrm{~nm}$. The first three UV peaks at 235, 310 and $360 \mathrm{~nm}$ are related to trace iron impurities. Pentavalent $\mathrm{V}^{5+}$ ions belong to the $\mathrm{d}^{0}$ configuration and did not exhibit $\mathrm{d}-\mathrm{d}$ visible bands but only the extra UV peaks at $360 \mathrm{~nm}$ can be related to the sharing of pentavalent vanadium together with combined absorption from $\left(\mathrm{Fe}^{3+}\right.$ ions). The extra visible peak at $580 \mathrm{~nm}$ can be related to the presence of trivalent vanadium. These results are also identified in $\mathrm{V}_{2} \mathrm{O}_{5}$-doped sodium borate glass [21]. Upon gamma irradiation, no distinct changes in the observed peaks before irradiation and no extra induced bands are observed. This result indicates that the presence of vanadium ions is assumed to cause some shielding effect towards gamma irradiation as observed in vanadium ions doped in various glasses [10, 21].

\subsubsection{Chromium Doped Glass}

The Cr-doped sample reveals before irradiation extended UV-visible spectrum consisting of strong and wide UV absorption revealing four peaks at about 235, 310, 350 and 370 $\mathrm{nm}$ followed by a peak at about $430 \mathrm{~nm}$ and finally a broad visible band centered at about $620 \mathrm{~nm}$. On subjecting this glass to gamma irradiation, the strong UV absorption retains its characteristic absorption peaks as before irradiation while the peak at $370 \mathrm{~nm}$ moves to $380 \mathrm{~nm}$ and the visible bands grow in their intensities.

This $\mathrm{Cr}_{2} \mathrm{O}_{3}$-doped sample reveals extended UV-visible absorption spectra which are represented by four UV peaks at 235, 310, 350 and $370 \mathrm{~nm}$ beside two visible peaks at 430 and $620 \mathrm{~nm}$. The collected absorption peaks are representing the presence of trace iron impurities (peaks 235, 310, 350 $\mathrm{nm}$ ), hexavalent chromium ions (peak $370 \mathrm{~nm}$ ) and the peaks at 430 and $620 \mathrm{~nm}$ are related to trivalent chromium $\left(\mathrm{Cr}^{3+}\right)$ ions present in octahedral coordination. Gamma irradiation is observed to cause limited increase in the intensities that promotes more identification of the absorption peaks. The experimental result indicates that gamma irradiation did not show any new induced peaks in this Cr-doped glass. The same behavior was reached by ElBatal et al [23] on spectral studies on $\mathrm{Cr}_{2} \mathrm{O}_{3}$-doped soda lime borate glass and on $\mathrm{Cr}_{2} \mathrm{O}_{3}$ doped borophosphate glass [24].

\subsubsection{Manganese-doped Glass}

The Mn-doped sample reveals strong and wide UV absorption showing two distinct peaks at about 235 and $310 \mathrm{~nm}$ and with a broad visible band centered at about $500 \mathrm{~nm}$. On gamma irradiation of the sample, the spectral features remain almost parallel to that before irradiation but with slight decrease in the UV absorption and slight increase in the visible absorption.

This $\mathrm{MnO}_{2}$-doped glass exhibits strong UV absorption with two distinct peaks at 235 and $310 \mathrm{~nm}$ which can be related to the presence of unavoidable trace iron ( $\mathrm{Fe}^{3+}$ ions) impurities. Also, this glass shows an extra broad visible band centered at about $500 \mathrm{~nm}$ which is related to the presence of trivalent manganese ions $\left(\mathrm{Mn}^{3+}\right)$ [9]. This sample after irradiation reveals that the spectral features are retained indicating stability of the glass after gamma irradiation without further induced bands. This can be related to some combined 
effects including shielding effect of the manganese ions together with the effect of base heavy strontium borate glass.

\subsubsection{Iron-doped Glass}

The Fe-doped glass exhibits strong and wide UV absorption spectrum revealing three distinct peaks at about 235, 310 and $350 \mathrm{~nm}$ and with no visible bands. Upon gamma irradiation, the spectral characteristics remain almost unchanged.

This $\mathrm{Fe}_{2} \mathrm{O}_{3}$-doped glass shows only strong UV spectrum with peaks at 235, 310 and $350 \mathrm{~nm}$ as the undoped sample and gamma irradiation produces no change in the spectral features. This confirms that UV peaks identified in the undoped sample are originating from trace iron impurities (specifically $\mathrm{Fe}^{3+}$ ions). The absence of induced visible bands can be related to the combined shielding effect of added (iron oxide ferric $\mathrm{Fe}^{3+}$ ions) together with the heavy strontium borate glass.

\subsubsection{Cobalt-doped Glass}

The Co-doped sample reveals strong ultraviolet absorption with two distinct peaks at about 235 and $310 \mathrm{~nm}$ connected with a distinct very broad visible band with three peaks at about 520, 580 and $640 \mathrm{~nm}$. Upon gamma irradiation, the UV absorption greatly decreases intensely while the first visible peak increases intensely with constancy of the two rests visible peaks.

The optical spectrum of this glass before irradiation exhibits combined UV-visible absorption. The UV peaks are related to trace iron $\left(\mathrm{Fe}^{3+}\right)$ impurities while the visible peaks at 520,580 and $640 \mathrm{~nm}$ can be attributed to the presence of octahedral $(520 \mathrm{~nm})$ and tetrahedral $(580,640 \mathrm{~nm})$ coordination of $\mathrm{Co}^{2+}$ ions [25]. Gamma irradiation causes minor changes in the intensities of some peaks but no new induced peaks are generated. The introduction of cobalt ions is assumed to cause some shielding effect towards gamma irradiation beside the effect of heavy strontium borate glass itself.

\subsubsection{Nickel-doped Glass}

The Ni-doped glass reveals strong UV absorption with two distinct peaks at 235 and $310 \mathrm{~nm}$ followed by a medium visible band at about $430 \mathrm{~nm}$ and with a final small broad band centered at about $840 \mathrm{~nm}$. On gamma irradiation, the UV absorption decreases intensely with a resolution of an extra peak at about $380 \mathrm{~nm}$ and the first visible band increases intensely while the last small broad band remains unchanged.

The optical spectrum of this NiO-doped glass extends from UV to visible regions revealing two UV peaks at 235 and $310 \mathrm{~nm}$ which are identified to be related to trace iron $\left(\mathrm{Fe}^{3+}\right)$ impurities. Also, the glass shows two further visible peaks at 430 and $840 \mathrm{~nm}$. These specific visible peaks indicate the presence of nickel ions in both octahedral $(430 \mathrm{~nm})$ and tetrahedral $(840 \mathrm{~nm})$ coordinations due to the close values of ligand field stabilization energy of both two coordinations [26]. Gamma irradiation causes the resolution of an extra induced peak at $380 \mathrm{~nm}$ which is related to $\mathrm{Fe}^{3+}$ ion when the percentage of iron increases more than the do- pant ppm level. This indicates a photochemical conversion of some $\mathrm{Fe}^{2+}$ ions to capture positive holes and are transformed to $\mathrm{Fe}^{3+}$ ions.

\subsubsection{Copper-doped glass}

The Cu-doped glass exhibits a strong UV absorption revealing three peaks at 235,310 and $350 \mathrm{~nm}$ followed by a very broad visible band centered at about $800 \mathrm{~nm}$. Upon gamma irradiation, all the spectral characteristics of this glass remain unchanged.

The optical spectrum of this CuO-doped glass reveals strong UV peaks at 235, 310 and $350 \mathrm{~nm}$ previously assumed to be related to the presence of unavoidable trace iron impurities. The glass also exhibits a very broad band centered at $800 \mathrm{~nm}$ and this band is related to the presence of $\mathrm{Cu}^{2+}$ ions in distorted octahedral coordination [27]. The stability of the optical absorption of this glass after gamma irradiation is related to some shielding behavior of the glass containing $\mathrm{CuO}$ towards gamma irradiation.

\subsection{Infrared Absorption Spectral Data}

Fig. (3) illustrates the FT infrared absorption spectra of the undoped and TMs-doped strontium borate glasses. The FTIR spectrum of the undoped strontium borate glass reveals the following spectral features:

a. A medium peak at about $440 \mathrm{~cm}^{-1}$.

b. A small peak at about $540 \mathrm{~cm}^{-1}$.

c. A distinct band at about $680 \mathrm{~cm}^{-1}$.

d. A broad strong band extending from about 800-1200 $\mathrm{cm}^{-1}$ centered at about $920 \mathrm{~cm}^{-1}$.

e. A broad very strong band from $1200-1750 \mathrm{~cm}^{-1}$ revealing three peaks at about 1350,1400 and $1430 \mathrm{~cm}^{-1}$ with a kink at the decreasing lobe at about $1640 \mathrm{~cm}^{-1}$.

The introduction of $3 \mathrm{~d}$ TM ions with the doping level $(0.2 \%)$ is observed to cause no distinct changes in the IR spectral features observed in the undoped glass and the characteristic bands remain the same in their position or number.

The same IR spectra are recorded with similar bands after gamma irradiation

Also, gamma irradiation causes no variations in the number and position of the characteristic vibrational bands which are due to triangular and tetrahedral borate groups. It is important to mention that the intensity of the broad band at $1250-1700 \mathrm{~cm}^{-1}$ is relatively higher intensely than the broad band in the $800-1250 \mathrm{~cm}^{-1}$ range in all spectral curves of the prepared glasses.

Glasses are accepted to be materials of non-periodic arrangement which lack long-order and cannot be differentiated or identified by x-ray diffraction analysis. Infrared spectroscopic technique has proven to be a powerful tool to investigate the basic structural units involved within the network constitution of glasses [28]. Borate glasses in particular, have been the subject of numerous infrared studies, due to their interesting and peculiar structures as evidenced through some valuable articles [29-31]. Borate glasses provide a different system in comparison to other glass-forming 


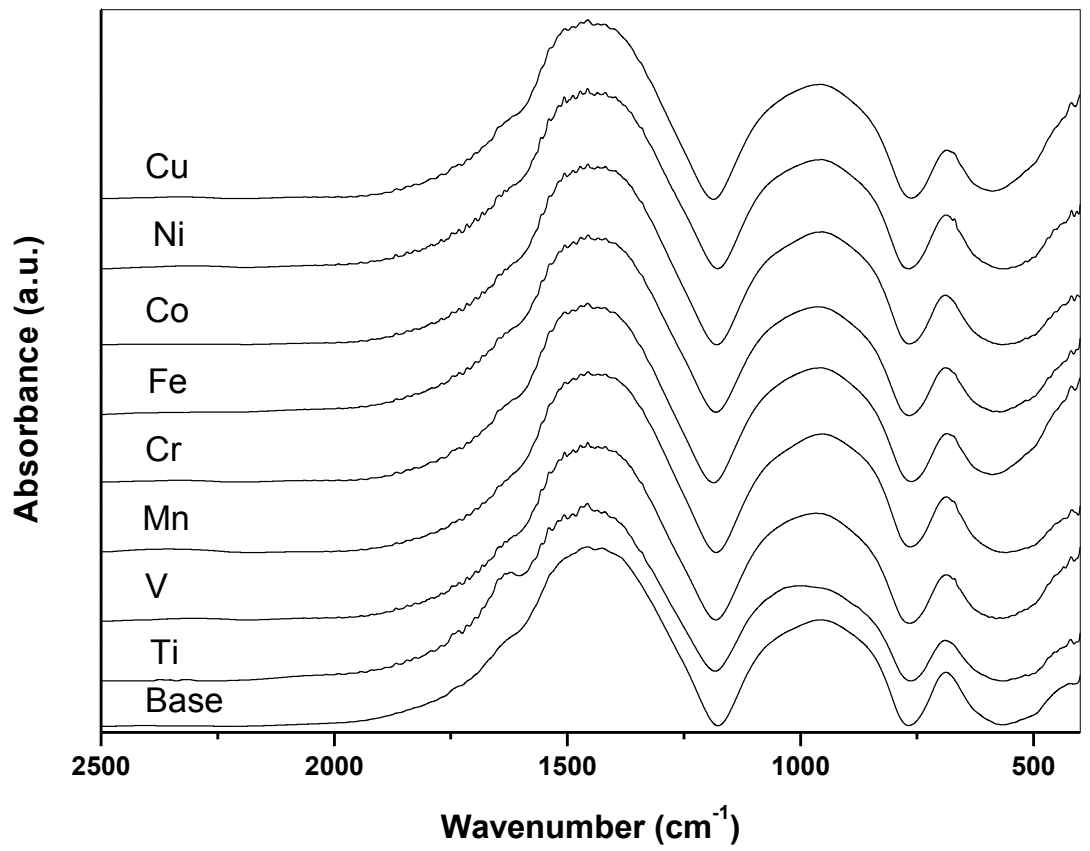

Fig. (3). FT infrared absorption spectra of base undoped and 3d transition metal-doped strontium borate glasses before gamma irradiation.

system to demonstrate the effectiveness of infrared spectroscopic analysis in glass science. Boron has the ability to change its three-fold coordination to accept the tetrahedral coordination by the addition of alkali oxides, alkaline earth oxides and some heavy metal oxides (e.g. $\mathrm{PbO}, \mathrm{Bi}_{2} \mathrm{O}_{3}$ ). This transformation process provides the formation of a range of atomic environments that can coordinate with the introduced cations or metal ions. This process of coordination transformation is different than that observed with both $\mathrm{SiO}_{2}$ and $\mathrm{P}_{2} \mathrm{O}_{5}$ where only the tetrahedral coordination is consistent in various network structural units within silicate and phosphate glasses. The most distinguished experimental data usually obtained from the IR spectroscopic studies on borate glasses are that the vibrating positions of triangular and tetrahedral borate units are quite different or occupying varying wavenumber positions. Extensive infrared studies on all borate glasses indicate that the stretching vibrations of tetrahedral borate units are active in the wavenumber range 800 $1200 \mathrm{~cm}^{-1}$ while the high frequency absorption at 1250-1600 $\mathrm{cm}^{-1}$ exhibits the modes of boron -oxygen triangular units $\left(\mathrm{BO}_{3}\right.$ and $\left.\mathrm{BO}_{2} \mathrm{O}^{-}\right)$. The low-frequency region of the mid region at $500-800 \mathrm{~cm}^{-1}$ is dominated by the bending vibrations or deformation modes of various borate units [7, 29-31].

\subsection{Interpretation of the Infrared Spectra Data and Ef- fect of Gamma Irradiation}

Infrared spectra of glasses and crystalline analogs have been used as a basis for the comparative qualitative identification of glass-forming structural units [7, 28-32]. Due to structural non-periodicity within glasses in the group arrangement, a complete vibrational analysis in glasses is not completely reached from ab initio point of view and an analysis is done primarily by comparing the IR spectra of these glasses with those of corresponding crystalline analogs for which the structure is completely known.
To interpret the complex IR spectra of the glasses in acceptable form, one of the repeated IR curves is chosen and a deconvolution method is applied to find out the different vibrational modes within the two very broad complex bands which result from tetrahedral and triangular borate groups as shown in Fig (4). The following interpretations are introduced for this deconvoluted spectrum [18, 19, 29-31]:

a) Tetrahedral $\left(\mathrm{BO}_{4}\right)$ borate stretching groups

1. The peak at $873 \mathrm{~cm}^{-1}$ can be related to vibrations of tri-, tetra- and pentaborate groups

2. The peak at $973 \mathrm{~cm}^{-1}$ can be related to vibrations of diborate groups.

3. The peak at $1080 \mathrm{~cm}^{-1}$ is related to tri-, tetra-, and pentaborate groups vibrations.

b) $\mathrm{BO}_{3}$ borate stretching groups

1. The peak at $1320 \mathrm{~cm}^{-1}$ is related to B-O vibrations of triangular groups.

2. The peak at $1457 \mathrm{~cm}^{-1}$ is related to B-O vibrations of triangular groups.

3. The peak at $1625 \mathrm{~cm}^{-1}$ is related to the water group vibrations.

c) B-O- bending

1. The peak at $770 \mathrm{~cm}^{-1}$ is related to vibrations of oxygen bridges between one tetrahedral and one trigonal boron atoms.

2. The peaks at $680-720$ are related to vibrations of oxygen bridges between two trigonal boron atoms.

d) Other cation vibrations

1. The peak at $460 \mathrm{~cm}^{-1}$ can be related to vibrations of $\mathrm{Sr}^{2+}$ cations. 


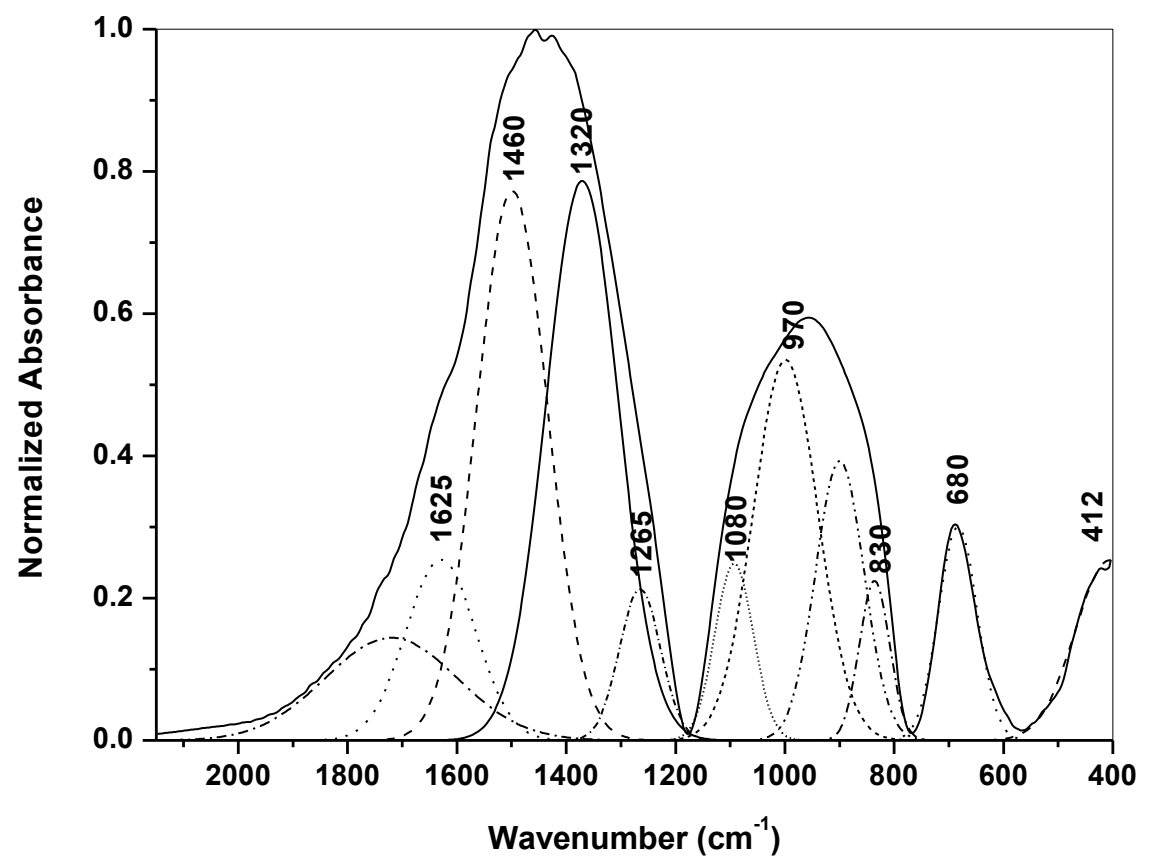

Fig. (4). Deconvoluted IR spectra of undoped strontium borate glass.

It is to be mentioned that the stability of the vibrational bands revealed in the IR spectra after gamma irradiation can be related to the introduction of $\mathrm{SrO}$ with relatively high percent $40 \%$ which increases the shielding behavior towards gamma irradiation as supported by the recent work of Kaundal et al [32]. Therefore, it is found profitable to mention in the legend of Fig. (3) that the same IR spectra are observed after gamma irradiation to avoid repetition of introducing the same spectral features.

\section{CONCLUSION}

Induced defects generated within prepared undoped and $3 \mathrm{~d}$ transition metal-doped strontium borate glasses were investigated and identified by combined optical and FT infrared spectroscopic measurements before and after gamma irradiation. The undoped binary strontium borate glass before gamma irradiation exhibits strong charge transfer ultraviolet absorption bands which are related to the presence of unavoidable trace iron impurities specifically $\mathrm{Fe}^{3+}$ ions contaminated within raw materials used for the preparation of this strontium borate glass. This strong UV absorption is also observed to be extended to all the doped samples beside the appearance of additional characteristic UV and visible bands due to each specific $3 \mathrm{~d}$ transition metal ions. Gamma irradiation of the base glass produces an increase in the intensity of the UV absorption generated by photochemical reactions during the irradiation process together with the resolution of an extra induced visible band due to nonbridging oxygen hole center (NBOHC) or boron hole center (BHC). Some 3d transition metal-doped glasses show some shielding behavior towards gamma irradiation. Infrared spectra of the prepared glasses indicate the appearance of vibrational modes due to both triangular and tetrahedral borate units with different and varying wavenumber positions and the triangular units vibrations are comparatively higher or intense than the vibrational modes of tetrahedral units. The introduction of either TM ions or gamma irradiation within the strontium borate glass causes no distinct changes in the main IR characteristic vibrational modes for borate units. The experimental optical data after gamma irradiation indicate or confirm the suitability of some TM ions-doped strontium borate glasses to act as radiation shielding candidates. Also, the strontium borate host glass promotes the presence of most transition metal ions in their high valence states without neglecting the lower valencies.

\section{CONFLICT OF INTEREST}

The authors declare that there is no conflict of interest regarding the publication of this article.

\section{ACKNOWLEDGEMENT}

Declared none.

\section{REFERENCES}

[1] Borate glasses, Crystals \& Melts, Proc. Intern. Conf. on Borate Glasses, Crystals \& Melts, Ed. M.D. Ingram, Soc Glass Technol, Sheffield 2004; p. 282.

[2] Ezzeldin FM. Leaching and mechanical properties of cabal glasses developed as matrices for immobilization high-level wastes, Nucl Instr Meth Phys Res B, 2001; 183: 285-300.

[3] Liang W, Rahman MN, Day DE, Marion NW, Riely GC, Mao JJ. Bioactive borate glass scaffold for bone tissue engineering. J NonCryst Solids 2008; 354: 1690-6.

[4] Ouis MA, Abdelghany AM, ElBatal HA. Corrosion mechanism and bioactivity of borate glasses analogue to Hench's bioglas. Process Appl Ceram 2012; 6: 141-9.

[5] Abdelghany AM, ElBatal HA, EzzElDin FM. Bone bonding ability behavior of some ternary borate glasses by immersion in sodium phosphate solution. Ceramics Int 2012; 380: 1105-13.

[6] Martinez AL, Lebullengc R, Feitosa CAC, Hernandez AC. Semitransparent barium borate surface crystallization for second harmonic generation. J Non-Cryst Solids 2005; 351: 1372-6.

[7] Kamitsos EI. Infrared studies of borate glasses. Phys Chem Glasses 2003; 44: 79-87. 
[8] Markova TS, Yenush OV, Polyokova IG, Pevzner BZ. Glass property calculations and prediction of new compounds on the basis of raman spectroscopy of borate glasses. Phys Chem Glasses. Eur J Glass Sci Technol, 2006; 47: 476-83.

[9] Bamford CR. Colour Generation and Control in Glass, Glass Science and Technology. Amsterdam:Elsevier Scientific Publishing Company 1977.

[10] ElBatal HA, Ghoneim NA. Absorption spectra of gamma-irradiated sodium phosphate glasses containing vanadium. Nucl Instr Meth Phys Res B 1997; 124: 81-90.

[11] ElBatal FH, ElKheshen AA, Azooz MA, Abo-Naf SM. Gamma ray interaction with lithium diborate glasses containing transition metals ions. Opt Mater 2008; 30: 881-91.

[12] Ghoneim NA, ElBatal HA, Abdelghany AM, Ali IS. Shielding behavior of $\mathrm{V}_{2} \mathrm{O}_{5}$ doped lead borate glasses towards gamma irradiation. J Alloy Comp 2011; 509: 6913-9.

[13] ElBatal FH, Hamdy YM, Marzouk SY. UV-visible and infrared absorption spectra of transition metals-doped lead phosphate glasses and the effect of gamma irradiation. J Non-Cryst Solids 2009; 355: 2439-47.

[14] Friebele EJ. Optical properties of glass. In: Uhlmann DR, Kreidl NJ Eds. Westerville: American Ceramic Society 1991; p. 205.

[15] Sigel GH, Ginther RJ. The effect of iron on the ultraviolet absorption of high purity soda-silica glass. Glass Technol 1968; 9: 66-9.

[16] Cook L, Mader KH. Ultraviolet transmission characteristics of a fluorophosphate laser glass. J Am Ceram Soc 1982; 65: 597-601.

[17] Duffy JA. Charge transfer spectra of metal ions in glass. Phys Chem Glasses 1997; 38: 289-94.

[18] Abdelghany AM. Combined DFT, Deconvolution Analysis for Structural Investigation of Copper - doped Lead Borate Glasses. Open Spec J 2012; 6: 9-14.

[19] ElBatal FH, Hamdy YM. UV-Visible and Infrared Spectroscopic Studies of Gamma-Irradiated Transition Metals-Doped Sodium Borate Glasses. Trans Indian Ceram Soc 2008; 67:193-9.

[20] Abdelshafi N, Morsi M. Optical absorption and infrared studies of some silicate glasses containing titanium. J Mater Sci 1997; 32: 5185-9.
[21] Ghoneim NA, Marzouk MA, Daoud T, EzzElDin FM. Spectroscopic properties of gamma irradiated $\mathrm{TiO}_{2}$ doped lithium phosphate glasses. Ind J Phys 2013; 87: 39-47.

[22] Paul A, Chemistry of Glasses. $2^{\text {nd }}$ ed. NY: Chapman and Hall, 1990.

[23] ElBatal HA, EzzElDin FM. Interaction of $\gamma$-rays with Some AlkaliAlkaline-Earth Borate Glasses Containing Chromium J Am Ceram Soc 1993; 76: 523-9.

[24] Abdelghany AM, ElBatal FH, Azooz MA, Ouis MA, ElBatal HA Optical and infrared absorption spectra of $3 \mathrm{~d}$ transition metal ionsdoped sodium borophosphate glasses and effect of gamma irradiation. Spectrochim Acta A, 2012; 98: 148-55.

[25] ElBatal FH, Ouis MA, Morsi RMM, Marzouk SY. Interaction of gamma rays with some sodium phosphate glasses containing cobalt. J Non-Cryst Solids 2010; 356: 46-55.

[26] ElBatal FH, Morsi RM, Ouis MA, Marzouk SY. UV-visible, Raman and E.S.R. studies of gamma-irradiated NiO-doped sodium metaphosphate glasses. Spectrochim Acta A, 2010; 77: 717-26.

[27] ElBatal HA, Mandouh Z, Zayed H, Marzouk SY, ElKomy G, Hosny A. Gamma ray interactions with undoped and CuO-doped lithium disilicate glasses. Phys B, 2010; 405: 4755-62.

[28] Wong J, Angell CA. Glass Structure by Spectroscopy. NY: Marcel Dekker, (1976).

[29] Krogh-Moe J. Infrared Spectra of Boron Oxide and Alkali Borate Glasses, Phys Chem Glasses 1965; 6: 46-54.

[30] Kamitsos EI, Patsis AP, Karkassides MA, Chryssikos GD. Infrared reflectance spectra of lithium borate glasses. J Non-Cryst Solids 1990; 126: 52-67.

[31] Khalifa FA, ElBatal HA. Vibrational spectra of some binary and their corresponding glass ceramics. Ind J Pur Appl Phys 1997; 35(9): 579-86.

[32] aundal RS, Kaur S, Singh N, Singh KJ. Investigation of structural properties of lead strontium borate glasses for gamma-ray shielding applications. J Phys Chem Solids 2010; 71: 1191-5.

(C) El Batal et al.; Licensee Bentham Open.

This is an open access article licensed under the terms of the Creative Commons Attribution Non-Commercial License (http://creativecommons.org/licenses/ by-nc/3.0/) which permits unrestricted, non-commercial use, distribution and reproduction in any medium, provided the work is properly cited. 